\title{
Videoconsultation to overcome barriers during COVID-19
}

Amanda YR $\underline{\mathrm{Lam}},{ }^{1} M B B S, M R C P(U K), F R C P$, Estee CL $\underline{\text { Chan, }}{ }^{2}{ }_{M B A}, B . E n g E E E$, Cheryl MX Quek,${ }^{2} B A$, Yanjie Peng ${ }^{2} B E n g$, Shuan Khiag Yeo, ${ }^{3}{ }_{B B A}$, Rui Fen Chang, ${ }_{B B M}^{3}$, Xiaohui Xin, ${ }^{4}{ }_{M A}$, Su-Yen $\underline{\text { Goh }},{ }^{1}{ }_{M B B S, ~ M R C P(U K), ~ F R C P}$

On 23 January 2020, Singapore confirmed its first case of COVID-19. On 7 April 2020, the Singapore government implemented measures to curb community spread of COVID-19, which included discouraging non-essential movement. ${ }^{1,2}$

Since February 2020, Government Restructured Hospitals in Singapore began deferring non-urgent outpatient appointments. This aimed to facilitate physical distancing and reallocate healthcare resources to combat the pandemic. As the pandemic becomes increasingly prolonged, this strategy is unsustainable. There is increasing interest in using videoconsultations to ensure that patients receive essential medical care while minimising their risk of COVID-19 exposure. ${ }^{3,4}$

Prior to the pandemic, most departments within our institution did not have established videoconsultation services. We describe our experience with the rapid set-up of a videoconsultation service in the Singapore General Hospital Endocrinology Department during the COVID-19 pandemic.

The immediate goal was to maintain continuity of care for suitable patients despite disruption caused by the pandemic. The long-term goal was to use videoconsultations to provide highly accessible healthcare beyond the pandemic.

The team. Our core project team comprised physicians from the Endocrinology Department, engineers from the Innovation \& Technology office, and administrative executives from the Specialist Outpatient Clinic Operations Office. The core project team was supported by the Departments of Finance, Pharmacy, Legal, Clinical Quality and Performance Management, and Medical Informatics, together with the Integrated Health Information Systems (IHiS), the technology agency for Singapore's public healthcare sector.

As the lead of the core project team, a physician champion from the Endocrinology Department worked with team members to design service workflow, trained newly-onboarded physicians, and gathered feedback.
A team of 4 Patient Service Associates (PSAs) received training in videoconsultation service operations.

Timeline and elements involved. The service was designed to be congruent with the National Telemedicine Guidelines for Singapore, released by the Ministry of Health (MOH) in 2015. ${ }^{5}$ Registered doctors providing telemedicine services are required to comply with the 2016 Singapore Medical Council Ethical Code and Ethical Guidelines. ${ }^{6,7}$

Planning for the service commenced in early February 2020. Elements involved in establishing the service are detailed in Table 1. Videoconsultations were chosen over phone consultations, as this afforded physicians the ability to read visual cues and perform visual assessments. The teleconferencing platform Zoom was used to conduct videoconsultations. The first patients were seen on 18 February 2020. The pilot continued for 5 months.

Videoconsultation workflow. When attending in-person endocrinology consultations, the patient journey involves multiple physical touchpoints (Fig. 1). The workflow for the videoconsultation service pilot (Fig. 2) shows the following touchpoints: patient selection, enrolment and communications, appointment handling, conducting of videoconsultations, administrative tasks following videoconsultations, and handling emergencies.

Selection and enrolment of patients. During the COVID-19 pandemic, physicians across the institution reviewed all upcoming outpatient appointments and decided whether to proceed with original in-person appointments, or to defer non-urgent appointments. For physicians involved in the videoconsultation pilot, an additional option was to convert an in-person appointment to a videoconsultation.

We established selection criteria for patients suitable for videoconsultation, understanding that the limitations of videoconsultation include the inability to measure vital signs or perform physical examinations (Table 1). Most suitable patients had chronic stable conditions, including diabetes, hypertension, dyslipidaemia, and thyroid

\footnotetext{
${ }^{1}$ Department of Endocrinology, Singapore General Hospital, Singapore

${ }^{2}$ Innovation \& Technology, Department of Future Health System, Singapore General Hospital, Singapore

${ }^{3}$ Specialist Outpatient Clinic Operations Office, Singapore General Hospital, Singapore

${ }^{4}$ Health Services Research Unit, Singapore General Hospital, Singapore

Correspondence: Dr Amanda Yun Rui Lam, Department of Endocrinology, Singapore General Hospital, Academia, Level 3, 20 College Road, Singapore 169856. Email: amanda.lam.y.r@singhealth.com.sg
} 


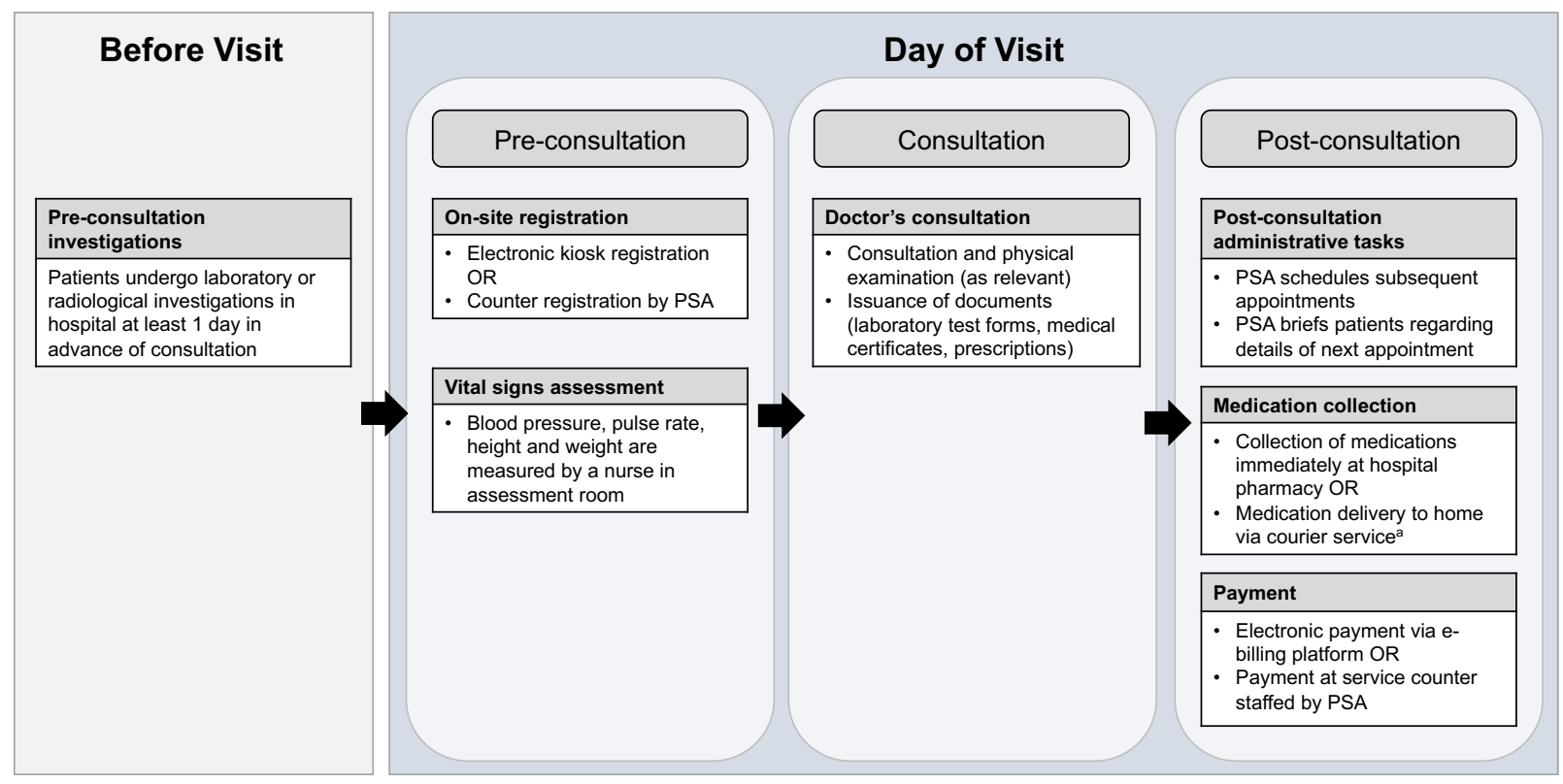

Fig. 1. Conventional consultation model - In-person consultations.

PSA: Patient Service Associate

a The medication delivery service is a pre-existing service since March 2019, which facilitates medication delivery to patients' homes (with the exception of restricted medications).

conditions. Patients were not permitted to self-enrol into the service without physician approval. Physicians ascertained patients' suitability for videoconsultation by reviewing clinical notes, then by phone call using a standard set of screening questions.

Physicians offered eligible patients the option of videoconsultation, and took verbal consent via telephone utilising a standard script. If the patient did not consent to a videoconsultation, they would proceed with an in-person consultation.

Patient communications and appointment handling. Videoconsultation appointments were created in the hospital's Outpatient Administrative System and on Zoom. Three days prior to their videoconsultation, patients received an email containing a Zoom user guide, their meeting ID and password, and a consent form that they were required to sign and return via email.

Patients could contact the hospital appointment centre to change their videoconsultation dates, or convert videoconsultation to in-person appointments if needed.

Conducting videoconsultations. Physicians conducted videoconsultation clinics in clinic rooms or private offices, separate from in-person clinics. Most physicians chose private offices, which were more convenient in terms of location, and eliminated the need for valuable clinic space and an on-site PSA. However, the absence of an on-site
PSA translated into physicians taking on the additional task of registering patients.

During the pilot, consultation slots were 30 minutes long, deliberately longer than the 10-minute slot for in-person consultations. This provided time to resolve technical and administrative difficulties during the acclimatisation period. Following the pilot, slot duration would be shortened to 15 minutes.

During consultations, patients verified their identities using photo identification. Physicians documented each videoconsultation session in the electronic health record.

Post-consultation, PSAs arranged for medications and documents to be delivered to patients via courier service, booked follow-up visits, and handled billing matters. Patients received text messages containing details of their next appointment, and links to the hospital's e-billing platform to make payment.

If required, an in-person consult would be arranged following the videoconsultation to address unexpected medical concerns. In the rare event that patients required urgent medical care, physicians would direct them to the Emergency Department.

\section{Pilot outcomes}

Clinical workload. Fig. 3 illustrates the clinical workload of the Endocrinology Department between February and 


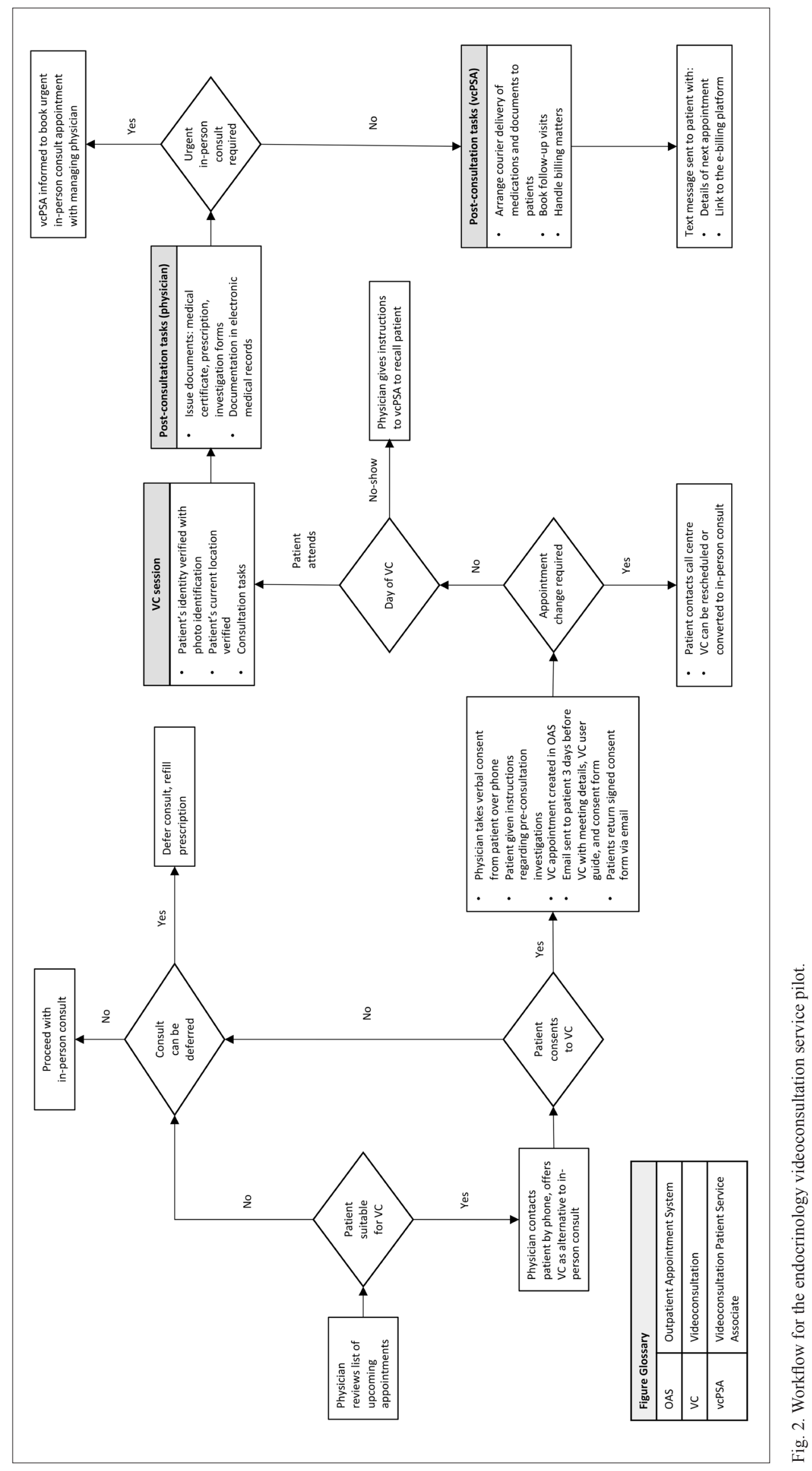


Table 1. Elements involved in establishing the endocrinology videoconsultation service

\begin{tabular}{lll}
\hline Element & Task & Details \\
\hline Regulatory body approval & Seeking approval from & Approval for the endocrinology videoconsultation service was \\
& institutional leaders & sought from \\
& (1) Head of Department \\
& (2) Division Chairman \\
& (3) Hospital's Medical Board
\end{tabular}

Ensuring service fulfilled all

legal and ethical requirements

$\begin{array}{ll}\begin{array}{l}\text { Establishing financing } \\ \text { framework }\end{array} & \begin{array}{l}\text { The endocrinology videoconsultation service was submitted via IHiS } \\ \text { eligibility }\end{array} \\ & \begin{array}{l}\text { Telehealth Programme Office for endorsement by the Director of Medical } \\ \text { Services (DMS). }\end{array} \\ & \begin{array}{l}\text { The endocrinology videoconsultation service was endorsed by } \\ \text { DMS to be eligible for subvention under an existing budget for } \\ \text { in-person consultations. }\end{array}\end{array}$

\begin{tabular}{|c|c|}
\hline & $\begin{array}{l}\text { Establishing billing system } \\
\text { with hospital finance department }\end{array}$ \\
\hline Software procurement & $\begin{array}{l}\text { Procuring accounts on the } \\
\text { Zoom videoconferencing platform }\end{array}$ \\
\hline
\end{tabular}

$\begin{array}{ll}\text { Setting up dedicated service } & \begin{array}{l}\text { A dedicated email account was created to facilitate communication } \\ \text { with patients. }\end{array}\end{array}$

$\begin{array}{ll}\text { Hardware procurement } & \begin{array}{l}\text { Internet-enabled devices for } \\ \text { conducting videoconsultations }\end{array}\end{array}$

Establishing patient Inclusion criteria

selection criteria
Incorporating time-limited

MediSave coverage into

financing framework

Setting up internal shared drive

As of 23 March 2020, the Ministry of Health Singapore extended the use of MediSave for videoconsultations of 7 selected chronic conditions for a time-limited period. Conditions relevant to the endocrinology service included diabetes, pre-diabetes, hypertension and lipid disorders.

Consultation charges were identical for in-person consultations and videoconsultations.

The same subsidy framework for conventional in-person consultations has been applied to videoconsultations.

Videoconsultations were conducted on the Zoom videoconferencing platform. A dedicated Zoom account with an IHiS-supplied Zoom licence was procured for the service.

A secure internal shared drive containing Excel spreadsheets was used to keep track of consultation tasks. The shared drive was accessible only by physicians and administrative staff involved in the service.

As internet separation is enforced at all Singapore public healthcare institutions, work computers have no internet access. An internet-enabled laptop was secured to facilitate videoconsultations.

(1) Literate in English and familiar with the use of video-call technology, or have caregivers who fulfilled these criteria.

(2) Vital signs monitoring should not be crucial to management. Alternatively, patients should have home vital sign monitoring records available.

(3) Physical examination should not be crucial to management.

(4) Patient should have sufficient medication supply to last 1 week from date of videoconsultation, to allow lead time for medication delivery services.

Exclusion criteria

Patients were excluded if physicians could not ascertain their clinical stability and suitability for videoconsultation. Such patients were:

(1) Patients consulting with the service for the first time.

(2) Patients who have not attended an in-person consultation within the last year. 
Table 1. Elements involved in establishing the endocrinology videoconsultation service (Cont'd)

\begin{tabular}{|c|c|c|}
\hline Element & Task & Details \\
\hline $\begin{array}{l}\text { Establishing service } \\
\text { workflow }\end{array}$ & $\begin{array}{l}\text { Establishing workflow for the } \\
\text { various patient touchpoints }\end{array}$ & $\begin{array}{l}\text { (1) Patient selection } \\
\text { (2) Patient enrolment and communications } \\
\text { (3) Appointment handling } \\
\text { (4) Conduct of videoconsultations } \\
\text { (5) Administrative tasks following videoconsultations } \\
\text { (6) Handling emergencies }\end{array}$ \\
\hline \multirow[t]{4}{*}{ Training of staff } & Physicians & $\begin{array}{l}\text { (1) Physicians were required to complete the Ministry of Health } \\
\text { telemedicine e-learning course }{ }^{10} \text { in order to familiarise themselves with } \\
\text { the safe use of telemedicine. } \\
\text { (2) Newly onboarded physicians were briefed by the department } \\
\text { physician champion on the ethical, technical and administrative aspects of } \\
\text { conducting videoconsultations using a standard set of training materials. } \\
\text { Physicians were trained to help patients resolve technical difficulties } \\
\text { during the consultation, such as dropped connections, } \\
\text { issues with sound and video connectivity. }\end{array}$ \\
\hline & $\begin{array}{l}\text { Videoconsultation Patient Service } \\
\text { Associates (PSAs) }\end{array}$ & PSAs received training in videoconsultation service operations. \\
\hline & & $\begin{array}{l}\text { PSAs were responsible for pre- and post-consultation tasks, including } \\
\text { appointment bookings, emailing patients, arranging for medication } \\
\text { delivery, and billing matters. }\end{array}$ \\
\hline & Appointment centre staff & $\begin{array}{l}\text { Appointment centre staff received training in appointment handling rules } \\
\text { for the videoconsultation service }\end{array}$ \\
\hline
\end{tabular}

IHiS: Integrated Health Information Systems; PSAs: Patient Service Associates

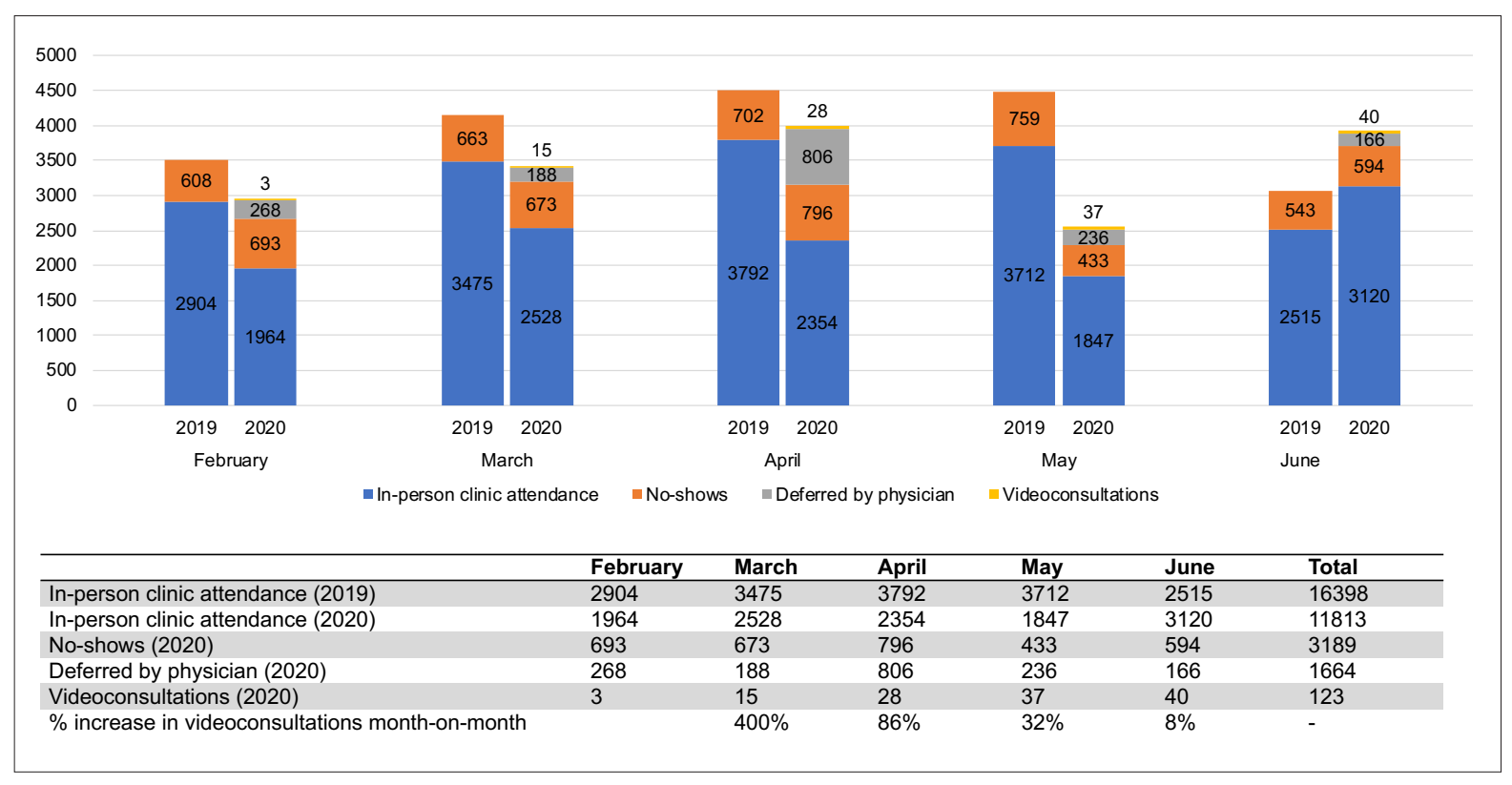

Fig. 3. Clinical workload of the Endocrinology Department (February - June in 2019 and 2020).

June in 2019 and 2020. Physicians actively deferred nonurgent outpatient appointments from February to mid-June 2020 due to the pandemic. Five endocrinologists were involved in the pilot. Of 16,789 existing appointments during this period, 1,664 (9.9\%) were deferred, and $123(0.7 \%)$ were converted to videoconsultations. No urgent in-person consults were required following videoconsultations.

Patient feedback. Verbal feedback from patients reflected general satisfaction with the convenience afforded by videoconsultations. They saved on transport 
costs and minimised time spent on hospital grounds. Technical difficulties were inevitable but quickly solved.

Several patients expressed that the convenience of the service could be enhanced if satellite centres were available island-wide for laboratory tests, negating the need to visit the hospital altogether.

Some suitable patients had upcoming appointments that ideally should not be deferred, yet declined the offer of a videoconsultation. They did not wish to visit the hospital at all, even for laboratory tests, citing fears of COVID-19 exposure. For this group, the current videoconsultation model could not completely address their needs.

Since 6 July 2020, electronic patient satisfaction surveys have been used to gather patient feedback. Over 9 weeks, the service achieved an average score of 4.9 out of 5 on the item "The videoconsultation session I attended met my health needs", to which responses were rated on a 5 -point Likert scale $(1=$ strongly disagree, $5=$ strongly agree).

Hurdles and solutions. We encountered several implementation hurdles during the pilot. Privacy and security concerns surrounding the videoconsultation platform were addressed by several safety measures: enforcing a waiting room feature and password authentication; disabling both meeting recording and inmeeting file transfer features; and allowing the meeting host to control content sharing.

Handling written consent forms was time-consuming for the patients and administrative team. Service workflow was therefore modified to involve only verbal consent taking using a standard script, with standardised documentation in patients' electronic notes.

Patients with chronic metabolic conditions initially could not use MediSave to pay for videoconsultation charges, as per in-person consultations. MediSave is a national medical savings account system, which may be used for outpatient expenses for certain chronic diseases. ${ }^{8}$ To facilitate physical distancing, $\mathrm{MOH}$ allowed the time-limited use of MediSave for videoconsultations for several chronic conditions in March 2020, ${ }^{9}$ removing financial barriers for patients consulting for diabetes, pre-diabetes, hypertension and dyslipidaemia.

Since conclusion of the pilot, publicity efforts on electronic and print media have increased videoconsultation uptake. Patients may express interest in videoconsultations via the hospital website, following which physicians may confirm their suitability.

Several hurdles still exist. While ubiquitous and user-friendly, Zoom was not specifically built as a videoconsultation platform. It lacks features which would enable more efficient videoconsultations, such as a patient registration and queue system, and integration into the hospital IT ecosystem. Administrative tasks therefore still involve manual manoeuvring between siloed systems. Solutions to securely integrate Zoom into the hospital's IT ecosystem are being explored. Other platforms may later be evaluated for suitability-forpurpose, user interface, cost, and compliance with international IT security standards such as the ISO 27001/2 and other relevant existing acts such as the Singapore Personal Data Protection Act 2012.

A time-motion study found that videoconsultations required more time per patient of physicians and PSAs than in-person consultations (27 and 12.7 minutes for physician and PSA, respectively for videoconsultations versus 15 and 7.3 minutes for physician and PSA, respectively for in-person consultations). There was however significant time savings for patients (15 vs 75 minutes for videoconsultations and in-person consultations, respectively, excluding travel time). Integration of Zoom with the IT ecosystem would be invaluable in reducing the time required of staff. While convenient for patients, videoconsultation clinics come with additional administrative tasks for physicians. A videoconsultation hub requiring only a low PSA-tophysician ratio, separate from existing physical clinics, is being explored to reduce physician administrative load.

Future plans. The service has since scaled up, involving 17 of 23 endocrinologists since July 2020, and patient numbers are expected to increase. Evaluation metrics to assess the future performance of the service include patient adoption, clinical safety, clinical effectiveness, cost impact, patient and staff satisfaction, and technical experience. A cost-minimisation analysis would be essential to define a scalable and sustainable service model.

Using lessons from the pilot, the team designed a toolkit that enables other departments to establish and customise their own videoconsultation services.

The COVID-19 pandemic has wrought global distress, but has also provided impetus to adopt new models of care. Our experience demonstrates that it is technically feasible to rapidly establish a videoconsultation service in a system where existing processes are oriented towards conventional consultations. This assuages previous concerns surrounding technical and administrative challenges, and that videoconsultations would not gain patient acceptance. A review of Singapore's health financing model and healthcare infrastructure will be important to ensure sustainability. The pandemic has prompted the first steps, but much work lies ahead to integrate videoconsultations into standard care. 


\section{REFERENCES}

1. Chen JIP, Yap JCH, Hsu LY, et al. COVID-19 and Singapore: From Early Response to Circuit Breaker. Ann Acad Med Singap 2020; 49:561-72

2. Tan THY, Toh MPSH, Vasoo S, et al. Coronavirus Disease 2019 (COVID-19): The Singapore Experience. A Review of the First Eight Months. Ann Acad Med Singap 2020;49:764-78.

3. Mehrotra A, Ray K, Brockmeyer DM, et al. Rapidly Converting to "Virtual Practices": Outpatient Care in the Era of Covid-19. NEJM Catal Innov Care Deliv 2020. Available at: https://catalyst.nejm.org/ doi/abs/10.1056/CAT.20.0091.

4. Greenhalgh T, Koh GCH, Car J. Covid-19: a remote assessment in primary care. BMJ 2020;368:m1182.

5. Ministry of Health, Singapore. National Telemedicine Guidelines for Singapore, 2015. Available at: https://www.moh.gov.sg/ docs/librariesprovider5/licensing-terms-and-conditions/nationaltelemedicine-guidelines-for-singapore-(dated-30-jan-2015).pdf. Accessed on 24 September 2020.

6. Singapore Medical Council. Telemedicine and Issuance of Online Medical Certificates, 18 April 2018. Available at: https://www.moh. gov.sg/docs/librariesprovider5/default-document-library/joint-smcand-moh-circular-on-teleconsultation-and-mcs.pdf. Accessed on 24th September 2020.

7. Singapore Medical Council. Ethical Code and Ethical Guidelines 2016 Edition, 13 September 2016. Available at: https:/www. healthprofessionals.gov.sg/docs/librariesprovider2/guidelines/2016smc-ethical-code-and-ethical-guidelines---(13sep16).pdf. Accessed on 24th September 2020.

8. Central Provident Fund Board. MediSave, 13 May 2020. Available at: https://www.cpf.gov.sg/Members/Schemes/schemes/healthcare/ medisave. Accessed on 26 May 2020.

9. Ministry of Health, Singapore. Time-limited extension of CHAS subsidy and use of MediSave for follow up of chronic conditions through video consultations in view of COVID-19. Available at: https:// www.moh.gov.sg/covid-19/vc. Accessed on 24 September 2020.

10. Ministry of Health, Singapore. Licensing Experimentation and Adaptation Programme (LEAP) - A MOH Regulatory Sandbox, 15 April 2020. Available at: https:/www.moh.gov.sg/home/our-healthcaresystem/licensing-experimentation-and-adaptation-programme-(leap)--a-moh-regulatory-sandbox. Accessed on 26 May 2020. 